\title{
Postlingual non-syndromic genetic deafness
}

INSERM

\section{Source}

INSERM. (1999). Orphanet: an online rare disease and orphan drug data base. Postlingual non-syndromic genetic deafness. ORPHA:216452

Postlingual non-syndromic genetic deafness is a rare, genetically highly heterogeneous otorhinolaryngologic disease, resulting from inner and/or middle ear or auditory nerve anomalies, typically characterized by progressive, bilateral, moderate to profound hearing loss (mean sensorineural hearing impairment equal to $40 \mathrm{~dB}$ or more for 500-, 1,000-, and 2,000- $\mathrm{Hz}$ frequency tones in the better ear) which occurs after the onset of speech development and is not associated with visible external ear abnormalities or any other medical problems. Language development is not initially significantly delayed.. 